\title{
Study the efficacy of platelet rich plasma and local corticosteroid injection for treatment of chronic plantar fasciitis
}

\author{
Munin Borgohain, Raskin Phukon* \\ Department of Orthopaedics, Assam Medical College and Hospital, Dibrugarh, Assam, India \\ Received: 06 December 2019 \\ Revised: 02 January 2020 \\ Accepted: 03 January 2020 \\ *Correspondence: \\ Dr. Raskin Phukon, \\ E-mail: phukon.raskin24@gmail.com \\ Copyright: (c) the author(s), publisher and licensee Medip Academy. This is an open-access article distributed under \\ the terms of the Creative Commons Attribution Non-Commercial License, which permits unrestricted non-commercial \\ use, distribution, and reproduction in any medium, provided the original work is properly cited.
}

\begin{abstract}
Background: Plantar fasciitis is one of the most common causes of heel pain. Various methods of treatment are available but no ideal treatment has been defined in literature. Corticosteroid (CS) injections are being used as a gold standard but studies have shown its short-term effects and various complications. Recently, platelet rich plasma (PRP) has been advocated as a newer treatment option. The main aim and objective of this study is to compare the two modalities of treatment regarding both pain and functional scores and their complications.

Methods: This study was a prospective cohort study. Total 90 patients with chronic plantar fasciitis visiting orthopaedic outpatient department of Assam Medical College and Hospital, Dibrugarh from July 2018 to June 2019 were enrolled for the study after clearance from Institutional Ethics Committee and equally divided into two groups. Group A received PRP and Group B received CS injections. They were assessed with visual analogue scale (VAS) and foot and ankle ability measure (FAAM) score at day 0, at 1 month, 3 months and 6 months. Level of significance was set at $\mathrm{p}<0.05$.

Results: The score on VAS and FAAM improved from baseline for both the groups. CS showed better results at 1 month and 3 months but at 6 months, results of PRP were better. 3 patients had recurrences in CS group.

Conclusions: Corticosteroid injections provide immediate and short-term relief but PRP is beneficial with long term effects and without any complications.
\end{abstract}

Keywords: PRP, Corticosteroid injection, Plantar fasciitis, VAS score, FAAM score

\section{INTRODUCTION}

Plantar fasciitis is an inflammation and degeneration of the plantar fascia or plantar aponeuroses. The degenerative changes occur near the site of origin at the medial tuberosity of the calcaneus. ${ }^{1}$ There is a combination of repeated opposing forces acting on the fascia by action of the tendoachilles and the forefoot. This leads to microscopic tears in plantar fascia, which results in zones of hypoplasia and hyperplasia. ${ }^{2}$ In chronic conditions, the normal tissue is replaced by an angiofibroblastic hyperplastic tissue that spreads itself throughout the surrounding tissue creating a selfperpetuating cycle of degeneration. ${ }^{3}$ Diagnosis requires a thorough clinical history and physical examinations. It presents with sharp pain in the morning as first-step pain that improves with normal use during daytime and worsens with heavy use. ${ }^{4}$ Pain is exacerbated by passive dorsiflexion of the toes or standing on the tips of the toes. ${ }^{5}$ In the chronic phase, the pain becomes continuous and dull in nature. ${ }^{6}$ 
The aetiology of plantar fasciitis is not clearly defined, but several risk factors have been attributed. Individual risk factors include obesity, loss of ankle dorsiflexion, extensive work-related weight-bearing, standing on hard surfaces for prolonged period, female gender, high arches of the feet and flat feet. ${ }^{7}$ Calcaneal spur is commonly seen in foot X-rays in about $50 \%$ of patients with pain, but its correlation is still uncertain. ${ }^{8}$ Treatment consists of various methods such as rest, nonsteroidal antiinflammatory drugs, night splints, foot orthosis, stretching protocols and extra corporeal shock wave therapy. ${ }^{9}$ Though corticosteroid (CS) injections are considered a popular method of treatment, but provide short term relief and have a high frequency of relapse and recurrences. ${ }^{1}$ Platelet-rich plasma (PRP) is an ideal autologous biological blood-derived product, a concentrate of platelets prepared by ultracentrifugation of the whole blood sample from the patient. ${ }^{10}$ It is a rich source of cytokines and growth factors that attract reparative cells thereby stimulates the natural healing process. ${ }^{11}$ These agents are platelet-derived growth factor, transforming growth factor-beta 1, epidermal growth factor, insulin-like growth factor, fibroblast growth factor and vascular endothelial growth factor, which modulate neovascularization and angiogenesis, promote mitogenesis, improve local collagen production, and have anti-inflammatory effects by blocking cylcooxygenase- 2 enzyme production. ${ }^{12}$ Many studies have reported the use of platelet rich plasma in plantar fasciitis and chronic tendinopathy. ${ }^{13}$

We conducted our study to evaluate the effect of autologous PRP and local CS injection for treatment of chronic plantar fasciitis.

\section{METHODS}

This hospital based prospective study was carried out in the department of orthopaedics and collaboration with department of pathology, AMCH from July 2018 to June 2019 after clearance from institutional ethics committee.

The study included patients with age more than 18 years and having heel pain that is worse with first step in the morning or after a period of inactivity of at least 3 months duration. We excluded patients with age <18 years, history of CS injection in last 2 months, uncontrolled diabetes mellitus, dysfunctions of foot and ankle, haemorrhagic disorders and patients not giving informed consent.

\section{Study method}

Patients were randomly allocated into two parallel groups. Group A $(n=45)$ had received PRP while Group B $(n=45)$ received CS injection. For Group A patients, 20 $\mathrm{ml}$ of blood was collected in an acid citrate dextrose vacutainer and centrifuged at $1500 \mathrm{rpm}$ for 15 minutes to separate the blood into layers of red blood cells, buffy- coat of leucocytes and plasma. ${ }^{14}$ PRP was prepared under aseptic conditions as per the procedures standardised in the pathology department laboratory. $2 \mathrm{ml}$ of PRP was injected in the most tender point over the origin of the plantar fascia on the medial tubercle of the calcaneus, using the peppering technique by 22 gauze needles in a fan-shaped fashion. $0.5 \mathrm{ml}$ of PRP sent to laboratory for count estimation. Post injection, patients were rested for 15 minutes and then allowed to walk. They were advised to avoid strenuous activities and rest for 2 weeks. As autologous blood transfusion is being done there is no need of any cross-matching or blood grouping. Group B was infiltrated with $1 \mathrm{ml}$ of local CS (triamcinolone acetonide $40 \mathrm{mg}$ ). First, we took $1 \mathrm{ml}$ of $2 \%$ lignocaine, then mixed with $1 \mathrm{ml}$ of triamcinolone $(40 \mathrm{mg})$ and infiltrated according to the same technique. Patients were followed up at 1 month, 3 months and 6 months and subjected to the following for outcome evaluation. Pain intensity was assessed with visual analogue score (VAS).${ }^{15}$ Functional outcome was assessed with the foot and ankle ability measure score (FAAM). ${ }^{16}$ Results were recorded. $\mathrm{P}$ value less than $0.05,25 \%$ reduction in VAS and $25 \%$ increase in FAAM were taken as a successful result. The statistical analysis of data was performed using the computer program, Statistical package for social sciences (SPSS for windows, version 20.0. Chicago, SPSS Inc.) and microsoft excel 2010. Results on continuous measurements are presented as mean \pm standard deviation and compared using student $\mathrm{t}-$ test. Discrete data are expressed as number (\%) and are analysed using chi-square test and Fisher's exact test (where the cell count was $<5$ or 0 ). For all analyses, the statistical significance was fixed at 5\% level ( $\mathrm{p}$ value $<0.05)$.

\section{RESULTS}

A total of 90 patients who met the inclusion criteria were included and analysed.

\section{Visual analogue scale score}

At first visit, Group A patients had a mean VAS score of 8.16 which is comparable to 8.29 with Group $\mathrm{B}$, which is not significant statistically. At 1 month of follow up, the mean VAS score decreased to 4.16 in Group A. In Group $\mathrm{B}$, the mean VAS is found to be 3.87. At 3 months of follow up, mean VAS is 3.56 among Group A whereas it is 2.82 among Group B. At follow up of 6 months, Group A had a mean VAS of 1.53 as compared to 1.73 among Group B. These are significant statistically (Table 1).

\section{Foot and ankle ability measure at 0 day}

At first visit, Group A patients had a mean FAAM score of 34.02 as daily activities score and 29.72 as sports subscale score. This is comparable to Group B with 32.65 as daily activities score and 29.79 as sports subscale score. $\mathrm{p}$ values were not found significant statistically (Table 2). 


\section{Foot and ankle ability measure at 1 month}

Group A patients had a mean FAAM daily activities score of 66.30 and 52.64 as sports subscale score at 1 month follow up. Group B had 70.32 as usual activities of daily living score and 55.14 as sports subscale score. p values were statistically found to be significant (Table 3).

\section{Foot and ankle ability measure at 3 months}

Group A patients had a mean FAAM daily activities score of 67.72 and 61.39 as sports subscale score at 3 months follow up. Group B had 76.06 as usual activities of daily living score and 69.51 as sports subscale score, which were statistically found to be significant (Table 4).

\section{Foot and ankle ability measure at 6 months}

Group A patients had a mean FAAM daily activities score of 91.96 and 78.89 as sports subscale score at 6 months follow up. Group B had 89.81 as usual activities of daily living score and 74.72 as sports subscale score, which were statistically found to be significant (Table 5).

Table 1: Visual analogue scale of patients of both Group A and Group B.

\begin{tabular}{|llll|}
\hline Visual analogue score & Group-A (PRP) & Group-B (CS) & P value \\
\hline Day 0 & Mean \pm SD & Mean \pm SD & 0.15523 \\
\hline 1 month & $8.16 \pm 0.67$ & $8.29 \pm 0.55$ & 0.00506 \\
\hline 3 months & $4.16 \pm 0.60$ & $3.87 \pm 0.59$ & 0.03731 \\
\hline 6 months & $3.56 \pm 0.50$ & $2.82 \pm 1.50$ & 0.00555 \\
\hline
\end{tabular}

Table 2: Functional foot and ankle ability measure score at day 0.

\begin{tabular}{|llll|}
\hline FAAM (at 0 day) & Group-A (PRP) & Group-B (CS) & P value \\
\hline Usual activities of daily living & Mean \pm SD & Mean \pm SD & 0.07885 \\
\hline Sports subscale & $29.02 \pm 5.94$ & $32.65 \pm 2.99$ & 0.47098 \\
\hline
\end{tabular}

Table 3: Foot and ankle ability measure score at 1 month.

\begin{tabular}{|llll|}
\hline FAAM (at 1 month) & Group-A (PRP) & Group-B (CS) & P value \\
\hline Usual activities of daily living & Mean \pm SD & Mean \pm SD & 0.02697 \\
\hline Sports subscale & $52.30 \pm 6.99$ & $70.32 \pm 2.91$ & 0.00707 \\
\hline
\end{tabular}

Table 4: Foot and ankle ability measure score at 3 months.

\begin{tabular}{|c|c|c|c|}
\hline \multirow{2}{*}{ FAAM (at 3 months) } & Group-A (PRP) & Group-B (CS) & \multirow{2}{*}{ P value } \\
\hline & Mean \pm SD & Mean \pm SD & \\
\hline Usual activities of daily living & $67.72 \pm 6.24$ & $76.06 \pm 13.01$ & 0.04722 \\
\hline Sports subscale & $61.39 \pm 4.81$ & $69.51 \pm 11.52$ & 0.0347 \\
\hline
\end{tabular}

Table 5: Foot and ankle ability measure score at 6 months.

\begin{tabular}{|c|c|c|c|}
\hline \multirow{2}{*}{ FAAM (at 6 months) } & Group-A (PRP) & Group-B (CS) & \multirow{2}{*}{ P value } \\
\hline & Mean \pm SD & Mean \pm SD & \\
\hline Usual activities of daily living & $91.96 \pm 2.57$ & $89.81 \pm 3.87$ & 0.00114 \\
\hline Sports subscale & $78.89 \pm 5.42$ & $74.72 \pm 3.32$ & $<0.0001$ \\
\hline
\end{tabular}

In our study, 3 patients had recurrences of heel pain after treatment in the CS group. None in the PRP group showed recurrences. No other complications like infections, heel pad atrophy, plantar fascia rupture etc. were encountered in our study. There was no placebo control group. Also, follow up period was only up to 6 months. Absence of MRI for confirmation of diagnosis as well as to see changes in the plantar fascia after injection are some of the shortcomings we encountered in our study.

\section{DISCUSSION}

Our study has shown that VAS is better in patients treated with corticosteroid group at 1 month and 3 months as compared to those treated with PRP. The VAS is better at 
6 months for PRP group than CS group. We have seen better functional results with CS group at 1 month and 3 months than compared to those with PRP group. But at 6 months duration, PRP showed better functional results than CS group. This result is similar to the study by Yaratapalli et al. ${ }^{17}$ They divided the cases into two groups receiving platelet rich plasma and corticosteroid injections. They followed at 1 month, 2 months, 3 months and 6 months. Evaluation of VAS at 1 month, 2 months and 3 months showed a significant decrease in CS group as compared to PRP group. At the end of 6 months, the PRP group showed significant reduction in VAS compared to CS group. They had an initial visit functional outcome score of 32.8 and 34.1 among the PRP and CS respectively. At 1 month and 3 months there was a significant improvement in CS group as compared to the PRP group. At 6 months, the PRP group showed a significant increase in functional outcome as compared to CS group. This is also similar to study by Acosta-Olivo et al. ${ }^{18}$ They showed that results with corticosteroid group is better than PRP till 12 weeks. Thereafter at 16 weeks PRP group showed better results than corticosteroid group.

Corticosteroids are extensively used for the treatment of plantar fasciitis. This is, in fact, the second most frequently described in medical literature. The typical use of corticosteroid injection in musculoskeletal disorder is by suppressing the prostaglandin mediated inflammation. ${ }^{19}$ Histological studies show that plantar fasciitis is a degenerative disorder, with very limited chronic inflammatory process. Increased proliferation of fibroblasts along with secretion of proteoglycans are seen. CS also work by inhibiting fibroblast proliferation and expression of ground substance protein. ${ }^{20}$ The use of steroid injection has been reported to be useful in short term and only to a small degree. Various side effects have been reported such as plantar fascia tear, fat pad atrophy, abscess, osteomyelitis, etc. ${ }^{21}$ It has a high frequency of relapse and recurrences. This is probably because intrafascial injection may lead to permanent adverse changes within the structure of the fascia and because patient tend to overuse the foot after direct pain relief from injections. $^{22}$

In recent years, the use of platelet rich plasma has increased in diverse clinical situations such as biological and autologous therapeutic alternatives. Clinical studies have shown its use to be safe as well as effective. ${ }^{23}$ Platelet rich plasma is the concentration of platelets derived from the plasma portion of one's own blood. ${ }^{24}$ Tendons have a poor blood supply. It is difficult for these tissues to receive the nutrients needed to stimulate repair. ${ }^{25,26}$ PRP stimulates the proliferation of various cell types in cells and tisues. ${ }^{27}$ It also activates repair cells in the blood circulation. ${ }^{28}$ Within the alpha granules of platelets, more than 30 bioactive proteins are present such as fibrin, fibronectin, vitronectin and thrombospondin. Growth factors such as platelet derived growth factor (PDGF), transforming growth factor (TGF), vascular endothelial growth factor (VEGF), insulin like growth factor (IGF) are present. ${ }^{29}$ These factors activate some of the cells that play a function in tissue healing and thus provide soft tissue healing and bone regeneration. ${ }^{30}$ Excessive inflammation inhibits apoptosis and metalloproteinases activities. ${ }^{25}$ It also increases tenocyte proliferation and collagen expression in the injured area in tendon recovery. ${ }^{31}$ Early pain relief after PRP injection due to anti-inflammatory effect resulting from inhibiting cyclo-oxygenase enzymes by the cytokines from the platelets. Later beneficial effects are due to local cellular proliferation, neoangiogenesis and increased type 1 collagen production. ${ }^{32}$ Enhanced and accelerated healing with excellent long-term results can be achieved on combining PRP injection with eccentric and cyclic plantar fascia specific stretching exercises. ${ }^{33}$

\section{CONCLUSION}

Our study has shown local corticosteroid injection to be effective for immediate and short-term pain relief. But, PRP has shown greater effects both by decreasing pain and increasing functional scores at 6 months of treatment. Moreover, no any side effects were seen with PRP injections. Thus, PRP is more beneficial than corticosteroid for treatment of chronic plantar fasciitis.

Funding: No funding sources

Conflict of interest: None declared

Ethical approval: The study was approved by the institutional ethics committee

\section{REFERENCES}

1. Crawford F, Thomson CE. Interventions for treating plantar heel pain. Cochrane Database Syst Rev. 2003: 3.

2. Snider MP, Clancy WG, McBeath AA. Plantar fascia release for chronic plantar fasciitis in runners. Am J Sports Med. 1983;11(4):215-9.

3. Lemont H, Ammirati KM, Usen N. Plantar fasciitis: a degenerative process (fasciosis) without inflammation. J Am Podiatr Med Assoc. 2003;93(3):234-7.

4. Davis PF, Severud E, Baxter DE. Painful heel syndrome: results of nonoperative treatment. Foot Ankle Int. 1994;15(10):531-5.

5. Young CC, Rutherford DS, Niedfeldt MW. Treatment of plantar fasciitis. Am Fam Physician. 2001;63(3):467-74.

6. Healey K, Chen K. Plantar fasciitis: current diagnostic modalities and treatments. Clin Podiatr Med Surg. 2010;27(3):369-80.

7. Riddle DL, Pulisic M, Pidcoe P, Johnson RE. Risk factors for plantar fasciitis: a matched case-control study. JBJS. 2003;85(5):872-7.

8. Mohseni-Bandpei MA, Nakhaee M, Mousavi ME, Shakourirad A, Safari MR, Kashani RV. Application of ultrasound in the assessment of plantar fascia in patients with plantar fasciitis: a 
systematic review. Ultrasound Med Biol. 2014;40(8):1737-54.

9. Mushtaq N, Abbasian A, Cutts S, Obi N, Pasapula C, Chan W. Plantar fasciitis. Ann R Coll Surg Engl. 2013;95(3):229.

10. Dorotka R, Sabeti M, Jimenez-Boj E, Goll A, Schubert S, Trieb K. Location modalities for focused extracorporeal shock wave application in the treatment of chronic plantar fasciitis. Foot Ankle Int. 2006;27(11):943-7.

11. Hall MP, Band PA, Meislin RJ, Jazrawi LM, Cardone DA. Platelet-rich plasma: current concepts and application in sports medicine. Journal Am Acad Orthop Surg. 2009;17(10):602-8.

12. Ragab EMS, Othman AMA. Platelets rich plasma for treatment of chronic plantar fasciitis. Arch Orthop Trauma Surg. 2012;132(8):1065-70.

13. Barrett S, Erredge S. Growth factors for chronic plantar fasciitis. Pod today. 2004;17(11):37-42.

14. Sweeny J, Grossman BJ. Blood collection, storage and component preparation methods. Tech Manual 14th edition. Bethesda MD, Am Assoc Blood Banks; 2002: 955-8.

15. Dixon JS, Bird HA. Reproducibility along a $10 \mathrm{~cm}$ vertical visual analogue scale. Ann Rheum Dis. 1981;40(1):87-9.

16. Martin RL, Irrgang JJ, Burdett RG, Conti SF, Swearingen JM Van. Evidence of validity for the Foot and Ankle Ability Measure (FAAM). Foot Ankle Int. 2005;26(11):968-83.

17. Yaratapalli SR, Nageswaran J, Chittaranjan S. Platelet rich plasma injection compared to corticosteroid injection in the treatment of chronic plantar fasciitis. IOSR J Dent Med Sci. 2015;14(9):44-9.

18. Acosta-Olivo C, Elizondo-Rodriguez J, LopezCavazos R, Vilchez-Cavazos F, Simental-Mendia M, Mendoza-Lemus O. Plantar fasciitis-a comparison of treatment with intralesional steroids versus platelet-rich plasma: a randomized, blinded study. J Am Podiatr Med Assoc. 2017;107(6):490-6.

19. Ahmed GS, Shaikh AH, Tofique M. Local Steroid Injection For Treatment Of Planter Fasciitis. Comparison Between Methylprednisolone And Dexamethasone. Med Channel. 2013;19:4.

20. Thomas JL, Christensen JC, Kravitz SR, Mendicino RW, Schuberth JM, Vanore J V, et al. The diagnosis and treatment of heel pain: a clinical practice guideline-revision 2010. J Foot Ankle Surg. 2010;49(3):S1-19.

21. Martinelli N, Marinozzi A, Carnì S, Trovato U, Bianchi A, Denaro V. Platelet-rich plasma injections for chronic plantar fasciitis. Int Orthop. 2013;37(5):839-42.
22. Tatli YZ, Kapasi S. The real risks of steroid injection for plantar fasciitis, with a review of conservative therapies. Curr Rev Musculoskelet Med. 2009;2(1):3.

23. O’Malley MJ, Vosseller JT, Gu Y. Successful use of platelet-rich plasma for chronic plantar fasciitis. HSS Journal®. 2013;9(2):129-33.

24. Soomekh DJ. Current concepts for the use of platelet-rich plasma in the foot and ankle. Clin Podiatr Med Surg. 2011;28(1):155-70.

25. Mishra A, Woodall Jr J, Vieira A. Treatment of tendon and muscle using platelet-rich plasma. Clin Sports Med. 2009;28(1):113-25.

26. Sánchez M, Anitua E, Orive G, Mujika I, Andia I. Platelet-rich therapies in the treatment of orthopaedic sports injuries. Sport Med. 2009;35:1-10.

27. Lucarelli E, Beccheroni A, Donati D, Sangiorgi L, Cenacchi A, Del Vento AM, et al. Platelet-derived growth factors enhance proliferation of human stromal stem cells. Biomaterials. 2003;24(18):3095-100.

28. Kajikawa Y, Morihara T, Sakamoto H, Matsuda K, Oshima Y, Yoshida A, et al. Platelet-rich plasma enhances the initial mobilization of circulationderived cells for tendon healing. J Cell Physiol. 2008;215(3):837-45.

29. Anitua E, Andia I, Ardanza B, Nurden P, Nurden AT. Autologous platelets as a source of proteins for healing and tissue regeneration. Thromb Haemost. 2004;91(01):4-15.

30. Alsousou J, Thompson M, Hulley P, Noble A, Willett K. The biology of platelet-rich plasma and its application in trauma and orthopaedic surgery: a review of the literature. J Bone Joint Surg Br. 2009;91(8):987-96.

31. Baksh N, Hannon CP, Murawski CD, Smyth NA, Kennedy JG. Platelet-rich plasma in tendon models: a systematic review of basic science literature. Arthrosc J Arthrosc Relat Surg. 2013;29(3):596-607.

32. Monto RR. Platelet rich plasma treatment for chronic Achilles tendinosis. Foot Ankle Int. 2012;33(5):379-85.

33. Virchenko O, Aspenberg P. How can one platelet injection after tendon injury lead to a stronger tendon after 4 weeks?: Interplay between early regeneration and mechanical stimulation. Acta Orthop. 2006;77(5):806-12.

Cite this article as: Borgohain M, Phukon R. Study the efficacy of platelet rich plasma and local corticosteroid injection for treatment of chronic plantar fasciitis. Int J Res Orthop 2020;6:281-5. 